\title{
¿El vuelo sin órganos? (El yo, lo oral y lo escrito en El obsceno pájaro de la noche) ${ }^{*}$
}

\author{
A flight without organs? (Ego, orality and writing \\ in El obsceno pájaro de la noche)
}

\author{
José Manuel Rodríguez \\ Universidad Católica de Temuco. Temuco, Chile. \\ jmrodriguez@uct.cl \\ OMAR SALAZAR \\ Universidad de Concepción. Concepción, Chile. \\ osalazar@udec.cl
}

Para Mario Rodríguez y la Universidad de Princeton

\section{RESUMEN}

El obsceno pájaro de la noche, de forma similar a las grandes novelas del Boom, comprende que el narrador omnisciente, al igual que el yo, es un pequeño tirano. Ya no el tirano del cuerpo, sino el señor del relato. La novela intentará liberarse de aquel dios mediante una serie de mecanismos. Entre ellos, postulamos, la coexistencia de dos narradores básicos. Uno, responsable del pretexto, discursivamente más cercano al estilo oral; el otro, responsable del texto, próximo a la omnisciencia y que, discursivamente, trabaja desde la perspectiva de la escritura. La teoría que se presta para un análisis de este tipo es la que estudia los cuerpos sin yo, la esquizofrenia. De allí que intentemos conjugar, a continuación, algunas propuestas del esquizoanálisis con otras propias de la narratología y el análisis textual para estudiar el estrato narrativo de El obsceno pájaro de la noche. Es importante destacar que en el desarrollo de nuestro estudio usamos

* Este trabajo fue escrito en el marco del proyecto Fondecyt 3080035: "Las ninfas, la literatura y el narrador”. Proyecto que financió nuestra estadía en los archivos donosianos de Princeton e Iowa. 
los manuscritos donosianos guardados en las bibliotecas de la Universidad de Iowa y de la Universidad de Princeton.

Palabras claves: Narrador, manuscritos, esquizofrenia, imbunche, oralidad, escritura.

\section{ABSTRACT}

El obsceno pájaro de la noche (The obscene night bird), in line to other great novels of Latin American Boom, understands that the omniscient author, like the ego, is a small tirant, though not a body tirant, but a tirant of narration itself. This novel tries to get free from that god through a series of devices. Among these devices we posit the co-existence of two basic narrators: one of them, resposible for the novel's pre-text, is closer to oral discourse, and the other one, responsible for the text proper, is closer to omniscience, and in regard to discourse, works within the framework of literacy. The theory that allows an analysis like this is the one that studies bodies that lack an ego, schizophrenia, and hence we try to join some schizoanalysis propositions and some of narratology and text analysis in order to study the narrative stratum of El obsceno pájaro de la noche. It is important to point out that for our study we have used Donoso's manuscripts, kept at the libraries of The Univesity of Iowa and Princeton University.

Keywords: Narrator, manuscripts, schizophrenia, imbunche, orality, literacy.

Recibido: 02/06/2010. Aceptado: 27/10/2010.

\section{PREÁMBULO}

T a última novela del Boom, El obsceno pájaro de la noche ${ }^{1}$, transcurre, Lfundamentalmente, en dos Casas. La primera es la Casa de Ejercicios Espirituales de la Chimba, viejo asilo donde habitan, entre otras, una serie de viejas maniáticas y un tanto brujas. El mozo de ese lugar es Humberto Peñaloza, el Mudito, personaje esencial del texto. La otra Casa se ubica en el fundo la "Rinconada". Allí el oligarca Jerónimo de Azcoitía construye un mundo poblado por monstruos, para encerrar a su hijo, Boy, también

${ }^{1}$ Nuestra afirmación se basa en que la novela fue publicada en 1970. Mismo año en que termina, desde el punto de vista editorial, el Boom. Ello se produce con la escisión de Barral editores. Casa que tanto promovió a los cinco escritores que conforman el, impresionante, fenómeno narrativo. 
monstruoso. Entre los seres que pueblan el fundo está la muy deforme enana Emperatriz, que obra como tal y como su nombre lo indica, es decir, como reina del lugar. También vive allí su esposo, el doctor cíclope Azula.

Otro personaje importante, que merodea por ambas Casas, es la Peta Ponce, vieja bruja, enemiga mortal de Peñaloza y antigua criada de la mujer de Azcoitía, Inés.

Es relevante señalar que Casa es lo mismo que decir novela para José Donoso. Así, por lo menos, sostiene el mismo autor: "la Casa es sinónimo de novela y, también, del mundo" (Notebook 17)².

El conocer las relaciones anotadas simplificará la lectura de los asuntos que intentamos abordar a continuación.

\section{LA NARRACIÓN Y LOS NARRADORES DEL BIRD ${ }^{3}$}

El interés por crear literatura es factible de relacionar con la esquizofrenia, pues la persona que decide escribir debe dar espacio a otro para que invente (encuentre) la fábula. Por ende, intentar la escritura ciertamente implica una fractura de la personalidad. Fractura que, según algunos, caracteriza a la esquizofrenia, como muestra una definición de ella: "disociación específica de las funciones psíquicas" (DRAE, 2001). Es necesario apuntar que considerar la escisión o fractura como una de las etapas del proceso de la escritura no es precisa, pues lo que se produce, más bien, es el surgimiento de otras personalidades. Luego, lo que ocurre es que tras la fractura, por el hueco, asoman otros. Diferentes autores han tratado el problema:

a. En una novela titulada Sostiene Pereira, leemos:

"creer que somos <uno> que tiene existencia por sí mismo, desligado de la inconmensurable cantidad de los propios yoes representa una ilusión" (76). Luego, el texto cita a dos médicos-filósofos, Ribot y Janet, quienes "ven la personalidad como una confederación de varias almas... que se pone bajo el control de un yo hegemónico que se ha impuesto a la confederación de nuestras almas" (76).

\footnotetext{
${ }^{2}$ Este cuaderno, Notebook, se encuentra en los archivos de Iowa y la referencia es: Correspondence, notebooks and manuscripts of Chilean writer José Donoso. 1942-1967. En: Special Collections Department, Main Library. University of Iowa. Iowa City.

${ }^{3}$ En los manuscritos donosianos la novela es llamada así.
} 
b. Lihn, hablando del poeta Lihn afirma:

Yo le dije al autor de estos sonetos/que soy una camisa de once varas/gato de siete vidas y dos caras/nada que ver con rimas y cuartetos/... Pero el tal, sordo y mudo me escribía... (1995: 78).

c. El Evangelio anota un diálogo en el que participó Jesús:

vino a su encuentro saliendo de entre los sepulcros un hombre... Cuando divisó a Jesús fue corriendo y se puso de rodillas... Jesús le preguntó: < ¿Cómo te llamas?>... contestó: <Me llamo Legión, porque somos muchos> (Marcos, 5, 1-10).

d. Borges, escribe:

En el sexto capítulo de la primera parte, el cura y el barbero revisan la biblioteca de don Quijote, asombrosamente uno de los libros examinados es la Galatea de Cervantes, y resulta que el barbero es amigo suyo y no lo admira demasiado, y dice que es más versado en desdichas que en versos y que el libro tiene algo de buena invención, propone algo y no concluye nada. El barbero, sueño de Cervantes o forma de un sueño de Cervantes, juzga a Cervantes (2002: 45-46).

La serie muestra a importantes escritores ubicando como un lugar central de su reflexión el problema de los múltiples otros, los yoes que habitan en los humanos y, por ende, en los autores. Nos acercamos entonces a lo que definiremos, para llamarlo de algún modo, un "esquizo problema narrativo" presente en la escritura. Problema al que atribuimos un carácter trinitario.

La primera fase ocurre en el momento en que un humano decide escribir ficciones. Tal decisión implica el triunfo del yo-escritor entre la manada de yoes. Nos encontramos así frente a un autor; sin embargo, éste no es el que escribe. Lihn lo muestra claramente, pues sostiene que otro escribía. Segunda parte del "esquizo problema": para alcanzar la narración será necesario encontrar un narrador entre la legión que habita la mente; tarea compleja, pues sabemos, de primera fuente, que en un estado de desorganización mental hay evidentes obstáculos para realizar las funciones ejecutivas, lo que lleva a una dificultad para mantener conductas motivadas y dirigidas a metas concretas. Tercera arista del "problema": el narrador se impone a una serie de voces que quieren hablar, tal como muestra Foucault en estas 
palabras tan enigmáticas: "Tras los personajes de la fábula... reina todo un teatro de sombras, con sus rivalidades y sus luchas nocturnas, sus justas y sus triunfos. Voces sin cuerpo se baten para contar la fábula" (1996: 215). Las palabras del filósofo trabajan en el mismo sentido propuesto hasta aquí: el narrador es un otro que surge desde los páramos de la mente, luego lucha con sus congéneres, los yoes, y termina apropiándose de la palabra con un solo fin: producir ficciones.

Notará el lector que el vincular a la narrativa con un rasgo de la esquizofrenia es un asunto complejo. De ahí que los textos que explicitan la relación, como es el caso de El obsceno pájaro de la noche, muestren esta complejidad. Ella se manifiesta en la producción de enunciados que no cubren adecuadamente las necesidades comunicativas, que incluyen referentes ambiguos, que no explicitan lo que debiera aparecer explícito. Pensamos que la novela es capaz de exhibir el problema porque está íntimamente ligada a la esquizofrenia. Su autor sufrió una crisis de la enfermedad provocada por ella. El mundo monstruoso que creaba se materializó frente a sus ojos. Estuvo internado en un hospital de Colorado y durante su recuperación escribió una carta a su esposa Pilar, y que guarda la biblioteca Firestone de la Universidad de Princeton: "Era la esquizofrenia. Hoy es mi primer paseo, el sol reverbera sobre la nieve" (Box 2, folder 8) ${ }^{4}$. Esta crisis nos autoriza a examinar lo que han dicho los teóricos de avanzada sobre el tipo de locura que atacó a Donoso. Deleuze y Guattari, nombres ilustres entre la vanguardia anotada, asedian en el Anti Edipo la teoría clásica de la esquizofrenia mostrando que ella reconoce tres "síntomas" básicos. El primero es la disociación, correspondiente al trastorno específico o déficit primario. El segundo es el autismo, es decir, el efecto de la "enfermedad", considerado como "un desapego de la realidad acompañada de la predominancia absoluta o relativa de la vida interior" (1995: 31). El tercero es "el ser en el mundo del hombre delirante en su mundo específico" (31). La crítica del Anti Edipo a la concepción clásica se funda en que "los tres conceptos tienen en común el relacionar el problema de la esquizofrenia con el yo... pero el yo es como el papá-mamá, hace tiempo que el esquizo ya no cree en él" (31). Luego, el problema del esquizo ya no parece ser la escisión: "Cada vez que se remite el problema del esquizofrénico al yo, sólo podemos probar una esencia o especificidad supuesta del esquizo, sea con amor y piedad, sea para esculpirla con desagrado. Una vez como yo disociado, otra como yo escindido, otra, la más coqueta, como yo que no había cesado de

\footnotetext{
${ }^{4}$ La referencia es: José Donoso Papers 1924-1996, bulk 1970-1990. En: Princeton University Library, Manuscript Division.
} 
ser..." (31). Estamos frente a una cuestión central conocida por la literatura y discutida por la filosofía: la presencia de múltiples yoes en la mente de los humanos. Ya vimos como la literatura discute el problema. Observemos ahora qué dice la filosofía sobre ello: Nietzsche, citado por Dumoulié, sostiene que "no hay sujeto, no hay yo, porque hay sujetos, hay yoes, en cada uno de nosotros" (1996: 122). Frente a estas palabras, el esquizoanálisis aparece como una herramienta que permite aproximarse a esa cuestión fundamental: la ausencia del sujeto único. Al contrario del psicoanálisis, que insiste en la existencia de un solo y gran yo.

"Autorizados" a examinar desde la óptica de la esquizofrenia la novela donosiana, gracias al concurso de la literatura, de la filosofía y de la propia novela, aclaramos que no es nuestro deseo ni (des)propósito hacer un esquizoanálisis de El obsceno pájaro de la noche. Las razones son múltiples, siendo la fundamental el hecho de que no practicamos esa disciplina, sino la crítica. Sólo nos interesa aquello de la ausencia del sujeto único, pues hemos constatado que el interés por despojarse del yo está en los orígenes del, llamado por Goic (1975), narrador-testigo-personaje de El obsceno pájaro de la noche. Así lo revelan los archivos Iowa: "Busca perderse, perder su soledad que es su esencia -no quiere tener esencia-y por ese camino llegar a ver lo que hay más allá... (Notebook 16: 4). Luego, al carecer de esencia ese narrador accede a lo otro: "Tiene la curiosa experiencia de 'ser todos los hombres', de fundirse con ellos. Su dueño y su esclavo. Se olvida de sí mismo. Cada vez hace algo distinto, porque al comenzar está con la mente en blanco" (Notebook 16: 4). Estas palabras parecen calcadas de otras, famosas, de Federico Nietzsche: "Yo soy todos los nombres de la historia". Pero, más allá de la similitud, interesa mostrar que en el momento de la disolución del yo aparece la posibilidad de crear: "El miedo como experiencia básica que conduce a la pérdida del auto control -y el hombre artista- el hombre saltimbanqui no se puede refrenar en caída por la pendiente de la creación. Fausto y Mefistófeles..." (Notebook 16: 5-6).

La serie de citas nos revela que la novela no comulga con la "superstición de los lógicos", no cree en la existencia de esencias (entre tales esencias está el yo). De ahí, por ejemplo, que El Bird no se interesa por el secreto, por esas cosas "que cuidadosamente se tiene reservada y oculta" (DRAE, 2001). La novela muestra claramente que no hay nada reservado ni oculto, que no hay esencia. Así lo vemos en el lugar que el Mudito y la encargada del asilo, la Madre Benita, revisan los trastos de una vieja recién muerta: “¿Para qué sigue abriendo y rompiendo envoltorios...? Si tiene que saber que no va a encontrar nada... sí, sí, Dios mío, hay algo dentro, algo duro definido... 
Sus dedos se entorpecen desanudando el lienzo: una bola de papel plateado. La raja, la rompe, el papel plateado queda convertido en escamas sobre la palma de su mano que tiembla..." (1997: 42). Podemos citar, en el mismo, sentido estas palabras de Inés de Azcoitía:

Madre páseme el espejito que hay dentro de la bolsa colorada que hay dentro de mi cartera negra, que está adentro de la bolsa de plástico, en un compartimiento con cierre que hay adentro de la maleta que está debajo de la cama (1997: 393).

La presencia del espejo en el fondo de una serie de paquetes revela que ahí, al igual que la bolita de papel, no hay nada esencial, sólo un objeto cuya esencia es la ausencia, de ahí que todo lo refleje.

Ahora, no sólo los paquetes carecen de esencia, sino también está despojada de ella una de las dos Casas del texto, la Casa de Ejercicios Espirituales de la Chimba. El asilo tenía una capilla en su interior, lugar donde había una lámpara del Santísimo, representación de Dios. La lámpara es robada por el padre Azócar, último capellán que allí ofició. La Madre Benita, junto al Mudito, observa el despojo. Ella comenta: "Mudito, que estás ahí, detrás del confesionario ayúdalo a apagar la luz del Santísimo y dejarnos sin la Presencia" (1997: 333). Desaparecida la santa imagen, la Casa queda sin centro y la capilla, convertida sólo en "otra habitación vacía" (1997: 335). Y si Casa es sinónimo de novela para Donoso, la novela queda vacía, sin centro.

Se observa que el texto trabaja en varios niveles la misma idea, la ausencia del centro en las cosas, en las Casas, en la novela, en las personas.

Ahora, el, presunto, centro del ser humano, ya lo sabemos, se llama yo. Luego, entender que yo único no existe provoca que el lugar que él supuestamente ocupa sea en realidad, "el lugar de un proceso, de una dinámica animada por un doble ritmo de concentración y de dilatación. De rigor y de llamado al caos... sin 'ser' propio, siempre se está en peligro de ser llevado hacia un descentramiento irreversible: la locura" (1995: 124). Ya sabemos que Donoso mismo sufrió los rigores del descentramiento. Es decir, asumió el peligro, al igual que el Mudito, su narrador-testigo-personaje. Leamos cómo ocurre el proceso de descentramiento en este último: "don Jerónimo le propone comprometerse en una acción que le llevará a comprometerse con la vida" (Notebook 21 c). Humberto se niega al compromiso, entre otras razones, pues él sabe que hacerlo sería establecer "una jerarquía, un mundo ordenado y significativo. Se niega... Él prefiere ser humano absurdo, sin significado, sin probar nada" (Notebook 21 c). Un ser humano absurdo, sin 
significado, por ende "sin ser", es equiparable, para la teoría de avanzada, al "sujeto-simulacro que no es sostenido por ningún principio, ninguna árje, no es un ser" (1995: 125).

Para entender de qué hablan cuando escriben simulacro estos pensadores tan opacos, recurrimos al capítulo "Simulacro y filosofía antigua", de la Lógica del sentido (Deleuze y Guattari, 1994). Allí se anota que Platón propone, en su teoría de las ideas, la existencia original que hace posible la presencia de la copia. Ese original se corresponde con una idea, la que, como se sabe, permanece intocada y pura fuera de la caverna. Pero esta distinción se le empieza a complicar cuando en El sofista discute sobre un tercer elemento: el simulacro, que ya no es una copia, pues ésta se construye por la similitud, y aquél se configura a partir de una disimilitud, una perversión del modelo. Luego, el discípulo de Sócrates propone distinguir entre las copias, las que, gracias a su semejanza a la idea, se constituyen en íconos, y los simulacros, meros fantasmas de aquélla. Propuesta cuyo fin es rechazar el simulacro y afirmar la superioridad de la copia, de la representación, es decir, de lo Uno y de lo Mismo. En este punto desaparece la pretendida superioridad, pues, el simulacro, al interiorizar una disimilitud, incluye lo Otro, acogiendo así a la alteridad.

Frente a lo anterior podemos sostener que el narrador-testigo-personaje del Bird es un simulacro de narrador omnisciente, pues él mismo desea "ser todos los hombres", es decir, acoge a la alteridad. Este gesto inscribe a la novela en una innovación relevante propuesta por la novela contemporánea y acogida por las grandes novelas del Boom. Hablamos de la "destitución" del narrador omnisciente. Pensemos, por ejemplo, en el narrador de Rayuela (1984) quién sugiere una lectura caótica del texto, la que revela el caos de su creación y ésta, en su definición omnipotente, origina un cosmos. De ahí que el creador del cosmos devenga un creador del caos y, por ende, pierda la omnipotencia dentro de su propia creación (la novela adquiere así una conformación caosmica, como diría Deleuze, es decir, tendría un carácter de caos-cosmos). Por otro lado, Cien años de soledad (1967) nos muestra un narrador loco que todo lo amplifica, que olvida personajes, etc. Para el narrador de Conversación en La Catedral (1970), hay varias situaciones que permanecen en la niebla. Así, por ejemplo, no queda claro si la madre de Zavalita se entera de la homosexualidad de su marido. La muerte de Artemio Cruz (1962) es contada por una multiplicidad de voces. Notamos, entonces, que El obsceno pájaro de la noche usa un procedimiento común a sus pares: destituir al señor de la omnisciencia.

Usar la palabra destitución no es gratuito, pues si anotamos la definición 
del término destituir, veremos que ésta es "privar de algo" (DRAE), podemos sostener que en el caso del narrador omnisciente ese algo del que se le priva es el poder, pues él no sólo sabe, sino que también puede. Por tanto opera como marca de poder en el discurso, es el dueño del discurso literario y, por ende, es amo y señor de los personajes, de la acción. A ese narrador omnisciente preferimos llamarlo supranarrador, pues él es quien construye, como dice Suleiman (1979), el súper sistema de la obra.

¿Cómo adquiere el poder el supranarrador?, es decir, ¿cómo se transforma en ese yo que controla a todos los demás? Una respuesta posible sería recordar unas palabras citadas: "tras los personajes de la fábula... reina todo un teatro de sombras, con sus rivalidades y sus luchas nocturnas, sus justas y sus triunfos. Voces sin cuerpo se baten para contar la fábula" (Foucault, por Deleuze, 1996: 215). Esas voces sin cuerpo son la multiplicidad, la manada que puebla la mente de toda mujer u hombre. Luego, al escribir, se produce una lucha entre los que pueblan la manada por apropiarse de la narración. Uno de ellos es capaz de capturar el poder. Generalmente el que logra la captura es el más fuerte. En el caso de narración, éste será el más disciplinado, el yo-narrador-omnisciente.

En el Bird el Mudito, cuando era el escritor Humberto Peñaloza, intenta capturar el poder total. Se instala en una torre de la "Rinconada", un observatorio, para escribir la saga de los Azcoitía, pero fracasa, se enferma y no logra escribir nada:

La cabeza de Humberto se desmoronó sobre su máquina de escribir. Sus brazos volcaron la lámpara del escritorio. Su cuerpo fue deslizándose de la silla y quedó hecho un montón de escombros en el suelo (1997: 281).

Esta zona del relato muestra, además del intertexto con Pedro Páramo (1981), que el relato sobre los sucesos del fundo no ha sido construido por un narrador panóptico, que es lo mismo que decir omnisciente. Por ende, "alguien", quien ya no es el Mudito, narra esa historia. Asunto que queda meridianamente claro cuando la enana Emperatriz explica por qué Peñaloza no pudo escribir sobre el fundo y sus habitantes:

Humberto Peñaloza no tenía la vocación de la sencillez. Sentía necesidad de retorcer lo normal, una especie de compulsión... fue tanto lo que complicó y deformó su proyecto inicial que es como si él mismo se hubiera perdido para siempre en el laberinto que iba inventando lleno de obscuridades y terrores... sí, eran más importantes sus obsesiones y sus odios que 
la realidad que le era necesario negar (503).

Emperatriz nos revela que ha de haber un narrador otro en la novela. Asunto que confirmamos con la crítica. Schopf, por ejemplo, sostiene que: "la escritura de El obsceno pájaro de la noche no conduce en una sola dirección... el sujeto disgregado de esta escritura -que es otro que el Mudito y los restantes narradores, pero no los excluye- este narrador que no exhibe casi forma o figura..." (1996: 227). La presencia del narrador que casi no exhibe "forma" la encontramos en una zona en que las viejas participan de un diálogo que amenaza con convertirse en infinito:

Habrá que hacer baberos con esta seda tan bonita, tan fina, seda celeste porque va a ser niño, no, los baberos de seda no sirven para nada porque después no se pueden lavar a mano no ven, y no vamos a estar mandándolos a la tintorería cada vez que la guagua los ensucie y las guaguas ensucian muchos baberos, varios cada día, pero si la seda se lava pues, Amalia, como vas a ser tan tonta que no sabes ni eso siquiera, la seda natural, la fina de veras, hay que rociarla bien rociadita y se deja orear un poco y entonces, después, con la plancha no muy caliente... (1997: 84).

Con los puntos suspensivos termina el diálogo y también el capítulo cuatro del Bird. Lo interesante de esos puntos, en apariencia inocentes, radica en que no son colocados allí por el Mudito, pues éste un poco antes intentó detener la locura de las viejas golpeando "las manos como en el recreo de un colegio para llamarles la atención y devolverlas a la realidad" (1997: 83).

Los puntos suspensivos adquieren importancia, pues muestran que el Mudito no tiene la autoridad suficiente para detener el flujo narrativo. Sólo logró que las viejas se callaran un rato. Luego, se impone nuevamente la locura hasta que aparece quien sí tiene el poder: aquel que ubica aquellas poderosas marcas gramaticales. Todo esto origina un problema de suyo interesante: la posibilidad de la existencia de un supranarrador en el Bird. Cornejo Polar anota, a este respecto, que ese supranarrador o hablante básico de la novela "aparece integrado en el orden destruido" (1975: 110). Sin embargo, lo identifica con el Mudito, pero al final de la novela muere incinerado y tras su muerte, la novela da cuenta de lo que sucede con sus cenizas. Obviamente el Mudito no puede contar nada después de muerto. Por ende, es otro el que narra el final. Otro reconocido por Schopf, como ya vimos, y también por Luengo: 
en la novela, el narrador básico despliega el marco referencial a partir del cual se proponen las reglas del juego de la lectura en cuyo interior se instala una segunda instancia narrativa desde la cual fluye un discurso segundo que corresponde al relato biográfico del personaje centro de la diégesis (1992: 59).

Entonces, ¿̨existe supranarrador en el Bird? La respuesta es compleja. Ya observamos que es capaz de poner puntos suspensivos y detener un relato que amenaza con ser infinito. Además, no desaparece completamente, pues está encargado de narrar uno de los dos macro-relatos que componen la novela. Incluso un crítico, Luengo, reconoce un narrador básico que despliega la superestructura del texto, de ahí que pareciera haber supranarrador en el Bird, esa sombra de la que hablaba Schopf. Pero vamos un paso más allá e insistimos que en el Bird hay dos narradores básicos. No existe un solo "marco referencial", existen dos. Nuestras investigaciones, ya publicadas, sobre la génesis del texto revelan que El obsceno pájaro de la noche es un intento de conjugar de dos ficciones: El último Azcoitía y Tres metros de cuerda (Rodríguez, 2008: 151 y siguientes). La segunda, a poco llevaría el nombre de la novela. El proceso fue complejo a tal punto que el mismo Donoso se pregunta: “¿Cómo diablos hacer calzar el Azcoitía con El obsceno pájaro?" (Notebook 23). Postulamos que, en realidad, no llegaron a "calzar" completamente. Permaneció la estructura basada en dos macro-relatos, de ahí los dos narradores. Informamos que hacer calzar los textos se tornó tan complejo que amenazó incluso con abortar la escritura del Bird. Así lo muestra una carta, guardada en Princeton, escrita por Donoso a su editor en España, fechada en 1968, en que le anuncia la imposibilidad de "lograr la novela" (Box 5, folder 9) y le propone substituirla por Este domingo. La solicitud se explica porque el autor ya había recibido adelantos por El obsceno pájaro de la noche.

Dados algunos fundamentos críticos y teóricos para apoyar nuestra tesis que afirma la existencia de dos narradores básicos en el Bird, y con el fin de consolidar en la medida de lo posible nuestros desarrollos, queremos ahora introducir otra óptica desde la cual examinar el estrato narrativo de la novela, esa óptica es el análisis sintáctico. Antes de ir a él, importa comentar la función de los manuscritos respecto de El obsceno pájaro de la noche: es evidente que ellos actúan como el pretexto de un objeto encaminado a la condición de texto propiamente dicho, es decir, un producto dotado de un alto grado de autonomía. Los manuscritos constituyen un testimonio, un documento en continuo proceso de revisión que, progresivamente, ad- 
quiere la condición de objeto disociado de su entorno cultural ${ }^{5}$, es decir, la escritura en un sentido literal. Ello explicaría el hecho de que en El obsceno pájaro de la noche aparezca, discursivamente, más de una voz; así, por una parte, en la obra permanecerían trazos de una voz cuya expresión escrita está subordinada a una mayor imbricación emisor/texto, pues se trata de la voz del pretexto, de esa especie de apunte destinado a convertirse en escritura cuya característica es construir enunciados menos trabados, pues tiende a la estructura sintáctica simple o coordinada. Por otra parte, en el relato está la voz de quien produce el texto, el objeto despersonalizado, autónomo, estructuralmente integrado cuyos enunciados son sintácticamente más extensos, más complejos, con predominio de las estructuras subordinadas. La primera voz, discursivamente, está más cerca de una ejecución oral; la segunda se ubica más cerca de un ejercicio orientado a complejizar el tejido del relato, a la organización del objeto unitario e independiente que es el texto escrito.

Mostramos, ahora, lo anunciado arriba, es decir, la presencia de ambos narradores desde el análisis sintáctico:

a. Voz primera, que corresponde al narrador-testigo-personaje:

La crónica no registra mi grito porque mi voz no se oye. Mis palabras no entraron en la historia. Pero alguien me señaló. Mil ojos vieron a don Jerónimo de Azcoitía sobre el tejado. Sonó el disparo. Mil testigos me vieron encogerme con el dolor de la bala que me rozó el brazo justo aquí, madre Benita, en el lugar donde años antes me había rozado el guante perfecto de don Jerónimo (129).

En la cita se observa qué enunciados tienden a estructurarse con una sintaxis en donde predomina la oración simple y la coordinación; ello implica, por un lado, una mayor fragmentación del discurso como también mayor compromiso con la materia narrada, en el sentido de no establecer distancia con el objeto escrito (Chafe, 1982); por otro lado, se expresa también un menor grado de intelectualización en el uso del lenguaje, es decir, menor evidencia de un trabajo explícito con los distintos niveles de la lengua que se oriente a generar con la escritura un objeto independiente de quien lo crea (Gallardo, 1986).

${ }^{5}$ La relación entre el pretexto y el texto había sido observada por Gallardo (1986) en un estudio sobre algunos textos fundacionales de la literatura castellana. 
b. Voz segunda, que corresponde al narrador heterodiegético:

No. Nadie contestaría. Año a año ella le iba proporcionando a Jerónimo informes sobre un desarrollo ficticio de Boy, ciñéndose a las líneas generales del proyecto inicial que se mantuvo en vigencia hasta que Humberto desapareció. Cuando Jerónimo supo lo de la huida de su secretario, estuvo a punto de disolverlo todo. Vino a la Rinconada para hacer una visita de inspección. Pero quedó tan encantado con el limbo que imperaba en la mente del Boy de cinco años, que decidió dejarlo todo en manos de Emperatriz, su prima tan querida, y del doctor Cristóforo Azula, un médico verdaderamente notable a juzgar por los resultados. Pero a medida que el niño fue pasando de la infancia a la pubertad y de la pubertad a la adolescencia, se hizo clarísimo que iba a ser imposible mantenerlo en el limbo (213).

En este fragmento se revela una tendencia a formular enunciados más extensos con predominio de la hipotaxis. En este caso, se puede inferir un distanciamiento del narrador con la materia narrada que favorece el ejercicio de la propiedad de intelectualización la lengua, un uso que expresa un alto grado de conciencia de su organización interna, de su dinámica de relación entre los elementos que integran un enunciado; en definitiva, ello implica construir un texto que muestra una mayor integración, lo que contribuye a percibirlo como un objeto autónomo, independiente de quien lo generó.

Recordemos que el narrador heterodiegético es el que asume la narración de los sucesos del fundo la "Rinconada", mismo lugar al que no pudo ingresar el narrador-testigo-personaje. Y si no pudo entrar, es imposible que pudiera narrar lo que allí sucede. Por ende, es evidente que la novela tiene dos narradores. Esta dualidad explica, por ejemplo, las reiteraciones que constantemente aparecen en el relato. Así el funeral de don Jerónimo es contado, sin variaciones, dos veces.

Un lugar en que se revelan claramente ambas presencias lo encontramos cuando aparece la duda sobre los hechos mágicos de la Conseja o historia de la bruja: "En un trozo, el popular, el inmortal que seguirá siendo contado durante siglos y siglos por viejas y trabajadores cansados y niños, el cacique escamotea a su hija del centro del relato, sustituyéndola por una vieja verrugosa cuya identidad no interesa a nadie, que expió lo que las dos mujeres debían haber expiado juntas si el personaje hasta entonces principal no hubiera desaparecido sin dejar huellas en el relato" (223). Estas palabras corresponden al narrador heterodiegético. Destacamos el alto nivel de integración del texto dada la presencia de oraciones subordinadas. 
Presencia que se sitúa en oposición a la fragmentación característica de un texto producido con oraciones simples o coordinadas, pues la subordinación obliga a retomar elementos ya mencionados mediante recursos gramaticales. Todo ello cohesiona el relato, reforzando su carácter autónomo como escritura.

Es muy interesante anotar que en el mismo monólogo, un tanto más adelante, aparece el otro narrador: "Quiere demostrármelo para reírse de mí porque ella sabe que yo perdí mi origen, o más bien sabe la verdad, que el doctor Azula me extirpó el ochenta por ciento que incluía a Humberto Peñaloza escritor, a Humberto Peñaloza secretario del prohombre, a Humberto Peñaloza de capa y chambergo recitando versos en las cantinas, a Humberto Peñaloza hijo del profesor primario, nieto de un maquinista de un tren de juguete que echó tanto humo que no se puede ver más atrás" (225). Al igual que en el caso comentado arriba, el narrador-testigo-personaje usa la oración simple y la coordinación. Y confirmamos su mayor compromiso con la materia narrada. No hay distancia. Él está involucrado en los hechos.

De los dos sistemas narrativos que exhibe la obra nos interesa fijar la mirada en el relato oral que construye aquel que intenta despojarse del yo. El que no desea asumir la omnisciencia, el que no quiere el poder, como muestran estas líneas: "Reconoce el deseo de ser Dios, no sólo jugar a serlo, y se atemoriza: reconoce en sí el poder hacerlo -que, incluso,- mentalmente lo ha hecho" (Notebook 21 c). Está claro que el ser Dios no es otra cosa que asumir la escritura. Asunción que: "le da miedo... se niega a hacerlo. Y el resto de su vida es huir de esta imagen de su propio poder" (Notebook 21 c). Huida que significará la disolución, la que ya hemos visto en el momento en que atribuimos al Mudito la condición de sujeto-simulacro. Acción consciente que queda aún más clara en el capítulo tres de uno de varios drafts o ensayos de la novela que se guardan en Iowa. Hablamos de la Perforated version. Allí, Peñaloza intenta deshacerse de un cuaderno donde está parte del Bird (nótese que Peñaloza se está refiriendo a los mismos cuadernos que hemos analizado):

Volví a tomarlo y me lo guardé. Un día, cuando tenga fuerza, me voy a deshacer de él, eso lo juro. No quiero ser nada y este cuaderno a ser algo, a tomar un perfil...en secreto y para mi solo, es cierto, algo intrascendente y efímero-pero algo... y no quiero... (56).

La disolución del Mudito se relaciona directamente con su asunción 
como vagabundo: "esa transfiguración, esa deshumanización que adquieren los vagabundos y que, algún día, yo sé que será mía” (61).

Se produce, entonces, un texto que será narrado por un sujeto que no desea el poder, un sujeto que abjura de un yo-hegemónico. Y a los cuerpos que habitan los sujetos que pretenden esa condición, el esquizoanálisis los llama Cuerpos sin Órganos o CsO. Noción en extremo sofisticada, que podemos simplificar, escandalosamente, diciendo que un $\mathrm{CsO}$ es un cuerpo que se ha despojado del yo-hegemónico. Despojo que en el caso de la novela se marcará en aquello que deviene Mudito, un imbunche. Monstruo usado por los brujos del sur de Chile para cuidar su cueva y, también, para potenciar sus hechizos. Capacidad que logra el imbunche gracias a que los palapechos, los brujos chilotes, lo despersonalizan. Él es un ser sin yo, por ende los hechizos de los brujos pueden pasar por su cuerpo. Éste deviene una pura intensidad. El imbunche como medio para narrar que usa el texto se transparenta cuando el Mudito intenta imbunchar, por medio de Emperatriz, la casa del fundo la "Rinconada". Allí, la enana da una fiesta y Peñaloza la convence de tapiar ventanas y puertas, es decir, quiere cerrar los orificios de la casa del Fundo. No lo logra, de ahí que la historia de "Rinconada" sea asumida por el narrador que permanece en las sombras. Postulamos, entonces, que imbunchar para narrar es la forma que privilegia El obsceno pájaro de la noche. Y el imbunche, insistimos, es un $\mathrm{CsO}$ que puede ser considerado "como lo más insignificante puesto en el lugar del significante absoluto a partir del cual se produce el texto: el cuerpo escribe" (Deleuze y Guattari, 1995: 125). Se entiende en este instante por qué postulamos que el uso de una noción con la que trabaja el esquizoanálisis, la multiplicidad de yoes, se constituye en una herramienta adecuada para operar con la narración en la novela.

Subsiste un problema: saber qué hace posible el relato. El Mudito deviene "cada vez más chico", pierde la voz, se vuelve loco, está sometido a la entera voluntad de las viejas. Y no sólo el narrador-testigo-personaje pierde el control, pues el narrador heterodiegético, también lo pierde. Pérdida que se observa cuando les ruega, les ordena a los monstruos que lo dejen en paz, recordándoles que: "yo los inventé" (434). Es interesante recordar que durante la crisis esquizofrénica del autor, uno de los delirios que lo acosaba era que los monstruos de la novela lo atacaban en su habitación del sanatorio. El hablar del autor nos obliga a introducir un necesario matiz en nuestra lectura del texto: Deleuze y Guattari afirman que el $\mathrm{CsO}$ es imposible, que nunca se logra plenamente. De allí el título interrogativo de este trabajo, “¿El vuelo sin órganos?" Siempre habrá, en toda novela, un cuerpo que la escribe y en 
ese cuerpo, uno de la manada de yoes es el que optó por la literatura. Él, en el caso del Bird, prefiere abandonar sus fastos, fusionarse con los otros y abandonarse a la multiplicidad, desbordando "la oposición entre lo uno y lo múltiple" (1995: 157), transformándose en un "continuum de todas las intensidades" (1995: 157), por el que pasan, precisamente, las intensidades narrativas que cruzan al Bird en su vuelo. Incluido el relato del narrador heterodiegético. El haber alcanzado una categoría tan compleja como es el devenir intensidad pudo haber hecho fracasar la escritura del texto, pues los flujos narrativos pudieron haber sido tantos y tan variados que su disposición, que podríamos llamar caosmica, al igual que la disposición de Rayuela, pudo haber sido imposible. Surge clara la pregunta: ¿Qué hace existir a la última novela del Boom? Respondemos con una clave nocturna que nos entrega el propio texto en el momento que el Mudito se declara "la séptima bruja” (56), sabemos que la bruja teje una red y como una araña siente las vibraciones en cada punto de esa red. Baste pensar en una de las primeras brujas de la literatura: Ariadna, princesa y maga que entrega un hilo a Teseo para que no se pierda en el laberinto. Una muestra del carácter arácnido del Bird está en el lugar en que dos monstruos son expulsados de la "Rinconada” y pasan en un motel la primera noche de la diáspora. Hasta allí llega la bruja Peta Ponce que no tiene nada que ver en la historia, simplemente aparece porque sintió una vibración en la red de la novela. Recordemos, una vez más, que esta palabra es sinónimo de Casa. Y la Casa de la Chimba "fue construida como una red" (371), entonces el relato está construido de ese modo. Si el lector aún considera insuficientes los argumentos que justifican el considerar al texto como dotado de una estructura reticular, informamos que había una centralita telefónica en la otra Casa de la novela, la Casa del fundo. Por ende, también esa Casa-novela se encuentra organizada como un tejido. Postulamos, entonces, que la novela existe gracias al devenir, desde narrador-testigo-personaje a escritor-bruja-imbunche, que sufre Humberto Peñaloza, pues es él quién teje una red sobre la que se enganchan los flujos narrativos del Bird. Y si no pudo entrar a la Casa de la "Rinconada", no importa, pues la persona que estaba a cargo de la centralita nombrada tenía orejas de chonchón, por ende también era una bruja y su red soporta la trama de esa zona del texto.

Finalmente concluimos que El obsceno pájaro de la noche se vincula profundamente con la oralidad, pues los más antiguos relatos son historias de brujas y, precisamente, sólo usando recursos de bruja fue posible articular las dos narraciones que configuran el gran texto donosiano. 


\section{REFERENCIAS}

Borges, Jorge Luis. 2002. Obras completas. Barcelona: Emecé.

Chafe, Wallace L. 1982. "Integration and Involvement in speaking, writing, and oral literature", en: Deborah Taunen, Spoken and Written language: Exploring orality and literacy. Vol. IX, Norwood, N. Jersey pp. 35-53.

Cornejo Polar, Antonio. 1975. "Encierro y substitución en El obsceno pájaro de la noche". En: José Donoso, la destrucción de un mundo. Buenos Aires: Ed. Fernando García Cambeiro.

Cortázar, Julio. 1984. Rayuela. Madrid: Editorial Alfaguara.

Deleuze, Gilles y Guattari, Félix. 1994. Lógica del sentido. Barcelona: Paidós. 1995. El Anti Edipo. Barcelona: Paidós.

Diccionario de la Real Academia Española. 2001. Diccionario de la lengua española (2 tomos). Madrid. Espasa Calpe.

Donoso, José. 1997. El obsceno pájaro de la noche. Santiago: Alfaguara. . Correspondence, notebooks and manuscripts of Chilean writer José Donoso. 1942-1967. En: Special Collections Department, Main Library. University of Iowa. Iowa City. . Notebook 16.

. Notebook 17.

. Notebook $21 \mathrm{c}$. . Notebook 23. . José Donoso Papers 1924-1996, bulk 1970-1990. En: Princeton University Library, Manuscript Division. . Box 2, folder 8 .

Dumoulié. Camille. 1996. Nietzsche y Artaud. Por una ética de la crueldad. México: Siglo XXI Editores.

Fuentes, Carlos. 1962. La muerte de Artemio Cruz. México: Fondo de Cultura Económica.

Foucault, Michel. 1996. De lenguaje y literatura. Barcelona: Paidós.

Gallardo, Andrés. 1986. "Alfabetismo en la Oralidad (El escritor medieval y la cultura del idioma)", en: Acta Literaria 10-11, pp. 133-143.

García Márquez, Gabriel. 1967. Cien años de soledad. Buenos Aires: Sudamericana.

Goic, Cedomil. 1975. "El narrador en el laberinto”. En: José Donoso: La destrucción de un mundo. Buenos Aires: Fernando García Cambeiro.

Lihn, Enrique. 1995. Por qué escribi (Antología). Santiago: Fondo de Cultura Económica. 
Luengo, Enrique. 1992. José Donoso. Desde el texto al metatexto. Concepción: Aníbal Pinto.

Rodríguez, José Manuel. 2008. "Alguien voló sobre el nido del Bird (un estudio de los manuscritos tempranos de El obsceno pájaro de la noche)", en Atenea 497, pp. 151-166.

Rulfo, Juan. 1981. Pedro Páramo. México D. F.: Fondo de Cultura Económica.

Schopf, Federico. 1996. "La mascarada de Donoso", en: Universum 11, pp. 223-231.

Suleiman, Susan. 1979. "La structure de l' apprentissage", en: Poetique 37, pp. 24-42.

Vargas Llosa, Mario. 1970. Conversación en La Catedral. Barcelona: Seix Barral. 